\title{
Iron and vitamin D3 levels in infants admitted with chest infection:
}

\section{A hospital-based study}

\section{Abstract}

Background and objective: Acute lower respiratory tract infection is one of the major causes of mortality and morbidity in children under five years of age, with many etiologies suggested to be among its predisposing risk factors. Research has suggested that iron and vitamin $D$ deficiencies may contribute to the vulnerability of acute respiratory infection among young children. This study aimed to assess the correlation between iron and vitamin D3 levels with acute lower respiratory tract infection.

Methods: The present study is a hospital-based case-control study conducted over a period of six months at Rapareen Teaching Hospital for Pediatrics in Erbil, Iraq. A total of 100 infants, 50 cases with and 50 controls without chest infection, aged four months to one year, attending the outpatient department, participated in the study.

Results: A statistically significant correlation was detected between vitamin $D$ level and acute lower respiratory tract infection $(P=0.029)$. Combined iron and vitamin $\mathrm{D}$ deficiency in cases compared to the control group was statistically significant $(P=0.004)$. Iron level alone and presence of anemia between cases and control were statistically not significant $(P=0.197$ and $P=0.216$, respectively).

Conclusion: The study shows a significant correlation between vitamin $D$ deficiency with increased susceptibility to acute lower respiratory tract infection. It was also found that combined deficiencies of $\mathrm{Hb}$ with vitamin $\mathrm{D}$ and iron with vitamin $\mathrm{D}$ significantly correlated with susceptibility to acute lower respiratory tract infection. It is concluded that treating these deficiencies may decrease the liability of this type of infection in infants.

Keywords: Iron; Vitamin D3; Chest infection.

\section{Introduction}

The term lower respiratory tract infection (LRTI) is usually used to include three main infectious diseases which are pneumonia, bronchiolitis, and bronchitis, or in the case when there is any combination of the three diseases. ${ }^{1}$ In developing countries acute LRTIs particularly pneumonia is the greatest single cause of death during childhood specifically for those who are under the age of five years, ${ }^{2}$ more than $70 \%$ of deaths due to pneumonia take place in sub-Saharan Africa and south-east Asia. ${ }^{3}$ Pneumonia is one of the lower respiratory infectious diseases which affects the health and threatens the life of infants and children, and the incidence and the mortality rate of it are significantly higher during the childhood period. ${ }^{4}$ On the other hand, bronchiolitis is a clinical syndrome which occurs in children $<2$ years of age, and it is characterized initially by upper respiratory symptoms like rhinorrhea then followed by infection of the lower respiratory tract and with inflammation, that causes wheezing or crackles. ${ }^{5}$ Pneumonia and bronchiolitis during the childhood period are the leading causes of mortality in children whose ages are less than five years. About 156 million new episodes of pneumonia annually worldwide, of which 151 million episodes are present in the developing countries. Important evidence showed that among the

${ }^{1}$ Department of Medical Physiology, College of Medicine, Hawler Medical University, Erbil, Iraq.

* Correspondence: toumms@yahoo.com 
important Risk factors that lead to pneumonia are undernutrition, lack of exclusive breastfeeding, low birth weight, indoor air pollution, lack of immunization especially of measles and overcrowding environment. $^{3}$ Balanced, good, and adequate nutrition is essential for the development of the immune system of the child and its maturity with the following development of resistance to many infections. So, it is stated that different forms of malnutrition which include iron deficiency may cause an indirect risk factor for ALRTI. ${ }^{6}$ The most common cause of anemia is Iron Deficiency Anemia (IDA) in developing countries. ${ }^{7}$ Iron deficiency anemia has adverse effects on the immune response in the human body results in low hemoglobin levels and impaired oxygenation of body tissues, and it has an independent risk factor for the development of lower respiratory tract infection in children. ${ }^{8}$ In children, IDA occurs most considerably from 6 months of age to 3 years, which is the same age period that repeated infections of respiratory tract occur. ${ }^{9}$ Several studies correlated between iron deficiency and ALRTI, among them is the study in Egypt that concluded IDA played a role in the development of ALRTI. ${ }^{10}$ Vitamin D3 is an important vitamin and an essential steroid hormone at the same time. This essential vitamin is produced in the body, particularly in the skin, when exposed to solar ultraviolet $B$ radiation then converting 7-dehydrocholesterol to pre-vitamin D3, this pre-vitamin is then converted to vitamin D3 within the liver. ${ }^{11}$ Vitamin $D$ has a big role in approximately all cells of the immune system. Many antigen presenting cells like the dendritic cells, $T$ and $B$ cells and macrophages express the vitamin $D$ receptor (VDR). ${ }^{12}$ In a study by Grant $^{13}$, showed that exposure to sun and its impact on the level of vitamin $D$ can assist in the explanation of the seasonality of respiratory infections in children, these infections particularly such as bronchiolitis and pneumonia, they reach the peak in the cold season of winter when the sunlight will be scant and disseminate in the summer. In a meta-analysis of 18 studies by Larkin et al. ${ }^{14}$ they found that VDD was associated with increasing the risk or the severity of ALRI in 13 studies of total 18. The aim of the study was to find the level of iron and vitamin D3 in infants with chest infection, find the correlation between iron deficiency and liability for chest infection, find the correlation between vitamin D3 and chest infection in infants, and find the correlation between combined deficiency of iron and vitamin D3 and susceptibility to chest infection.

\section{Methods}

\section{Setting of the study}

A hospital-based case-control study was carried out at Rapareen Pediatric Teaching Hospital in Erbil, Iraq, from January 2018 till June 2018. A total of 100 infants of both genders participated in the study aged from 4 months to 1 year old. Out of the 100 infants, 50 of them were diagnosed as LRTI (pneumonia, bronchopneumonia or bronchiolitis) at the time of the study by a specialist pediatrician and they represent the cases in the study, LRTI diagnosis was made according to specific criteria that rely on the symptoms and clinical signs like the presence of fever, tachypnea, chest retractions, cough, and crackles or rhonchi during chest auscultation for both pneumonia ${ }^{15}$ and bronchiolitis ${ }^{5}$ cases. The other 50 subjects, who had no respiratory infections, were taken as controls. They were age and sex matched to the case group. They represent the infants attending the outpatient department complaining from conditions other than respiratory system illnesses. After introducing the work to the mother or the caregiver of the infant, informed verbal consent was taken from them for the agreement of the participation of the infant in the study work. After getting the consent, the questionnaire that was specially designed for this study was explained to the mother, then after filled out. A detailed clinical history and physical 
examination were made for all cases and controls included in this study. A special focus was on cases with chest infection through the general examination of the infant, chest examination for signs of respiratory infection, and X-ray that had been taken for all of them. Measurement of the height and weight was done for all the participants in the study. All the participants were examined for possible rachitic signs.

\section{Sampling}

The area of blood sampling, mostly the cubital area of the arm, was sterilized, and efficient laboratory staff of Rapareen Hospital withdrew $4 \mathrm{ml}$ of blood from a superficial vein and were put in special tubes for investigation. The laboratory investigations included complete blood count (CBC), serum vitamin D3, serum iron, and serum ferritin. For the CBC test, $2 \mathrm{ml}$ of blood was taken and collected in the EDTA containing tube, then putting the tube in the Tube Roller Mixer for about 1 minute, then taking a sample from the tube and putting it into hematology analyzer autosampler (MYTHIC 22 / Switzerland). The data will be obtained seconds later and will show on the screen of the machine. For the vitamin D, ferritin and iron $2 \mathrm{cc}$ of blood was taken and putting in GEL \& Clot Activator tube then centrifuge for 10 minutes in Eppendorf 5702 centrifuge (5000 RPM) after separation of the serum taking a sample from that serum and putting it in Cobas C 311 machine for analyzing and giving the result for serum iron after about 10 minutes. The reference range for serum iron is $40-100 \mu \mathrm{g} / \mathrm{dl} .{ }^{16}$ For the serum ferritin and the vitamin $\mathrm{D}$ another part of the serum was put it in Cobas e 411 machine for 15 minutes (ferritin) 35 minute (vitamin D) and the machine automatically find out the results. The cut off for normal ferritin level in infants is $<12 \mu / \mathrm{L} .{ }^{17}$ For vitamin D3 regarding $[25(\mathrm{OH})$ D], 25 hydroxy vitamin $\mathrm{D}$, level the normal values are: Vitamin D Deficiency: $<20 \mathrm{ng} / \mathrm{mL}$, Insufficiency $21-29 \mathrm{ng} / \mathrm{mL}$, Sufficiency $>30$ $\mathrm{ng} / \mathrm{mL} .{ }^{18}$ For anemia diagnosis, a child is anemic when his hemoglobin level is lower than $11 \mathrm{~g} / \mathrm{dL} .{ }^{19}$

\section{Inclusion and exclusion criteria}

The inclusion criteria included any infant from both genders from four months to one year of age who had been admitted to Rapareen hospital for lower respiratory tract infection, either pneumonia, bronchopneumonia, or bronchiolitis. While the exclusion criteria were age less than four months or older than one year, any chronic disease like diabetes, chronic cardiac or renal disease, any chronic syndrome, malformations of the chest wall, and previous supplementation with vitamin D or iron.

\section{Statistical analysis}

Data were analyzed using the statistical package for the social sciences (version 22). Chi-square test of association was used to compare proportions. Fisher's exact test was used when the expected count of more than $20 \%$ of the cells of the table was less than 5 . The student's t-test of two independent samples was used to compare two means. A $P$ value of $\leq 0.05$ was considered statistically significant.

\section{Ethical approval}

This study was approved by the ethical committee of the College of Medicine, Hawler Medical University (Reference no. 1/22/ dated 22/11/2017).

\section{Results}

Table 1 shows that $44 \%$ of the cases were anemic compared with $32 \%$ of the control group, but the difference was not significant $(P=0.216)$. The proportion of cases with low serum iron $(52 \%)$ was higher than that of the $(40 \%)$ control $(P=0.252)$. No significant association was detected between serum ferritin and chest infection $(P=0.495)$. Regarding vitamin $D 3$, it was deficient among $46 \%$ of the cases compared with $24 \%$ of the controls $(P=0.029)$ (Table 1 and Figure 1). 
Iron and vitamin D3 levels in infants admitted .......

Table 1: Laboratory findings of the study groups.

\begin{tabular}{lccccccc}
\hline & \multicolumn{2}{c}{ Case } & \multicolumn{2}{c}{ Control } & \multicolumn{2}{c}{ Total } & \\
& No. & $(\%)$ & No. & $(\%)$ & No. & (\%) & P value \\
\hline Hb & 22 & $(44.0)$ & 16 & $(32.0)$ & 38 & $(38.0)$ & 0.216 \\
Nonemic & 28 & $(56.0)$ & 34 & $(68.0)$ & 62 & $(62.0)$ & \\
Iron & & & & & & & \\
Low & 26 & $(52.0)$ & 20 & $(40.0)$ & 46 & $(46.0)$ & $0.252^{*}$ \\
Normal & 21 & $(42.0)$ & 29 & $(58.0)$ & 50 & $(50.0)$ & \\
High & 3 & $(6.0)$ & 1 & $(2.0)$ & 4 & $(4.0)$ & \\
Ferritin & & & & & & & \\
Deficient & 0 & $(0.0)$ & 2 & $(4.0)$ & 2 & $(2.0)$ & $0.495^{*}$ \\
Normal & 50 & $(100.0)$ & 48 & $(96.0)$ & 98 & $(98.0)$ & \\
Vitamin D3 & & & & & & & \\
Deficient & 23 & $(46.0)$ & 12 & $(24.0)$ & 35 & $(35.0)$ & 0.029 \\
Insufficient & 7 & $(14.0)$ & 16 & $(32.0)$ & 23 & $(23.0)$ & \\
Normal & 20 & $(40.0)$ & 22 & $(44.0)$ & 42 & $(42.0)$ & \\
Total & 50 & $(100.0)$ & 50 & $(100.0)$ & 100 & $(100.0)$ & \\
\hline By Fishers & & & & & & & \\
\hline
\end{tabular}

*By Fisher's exact test.

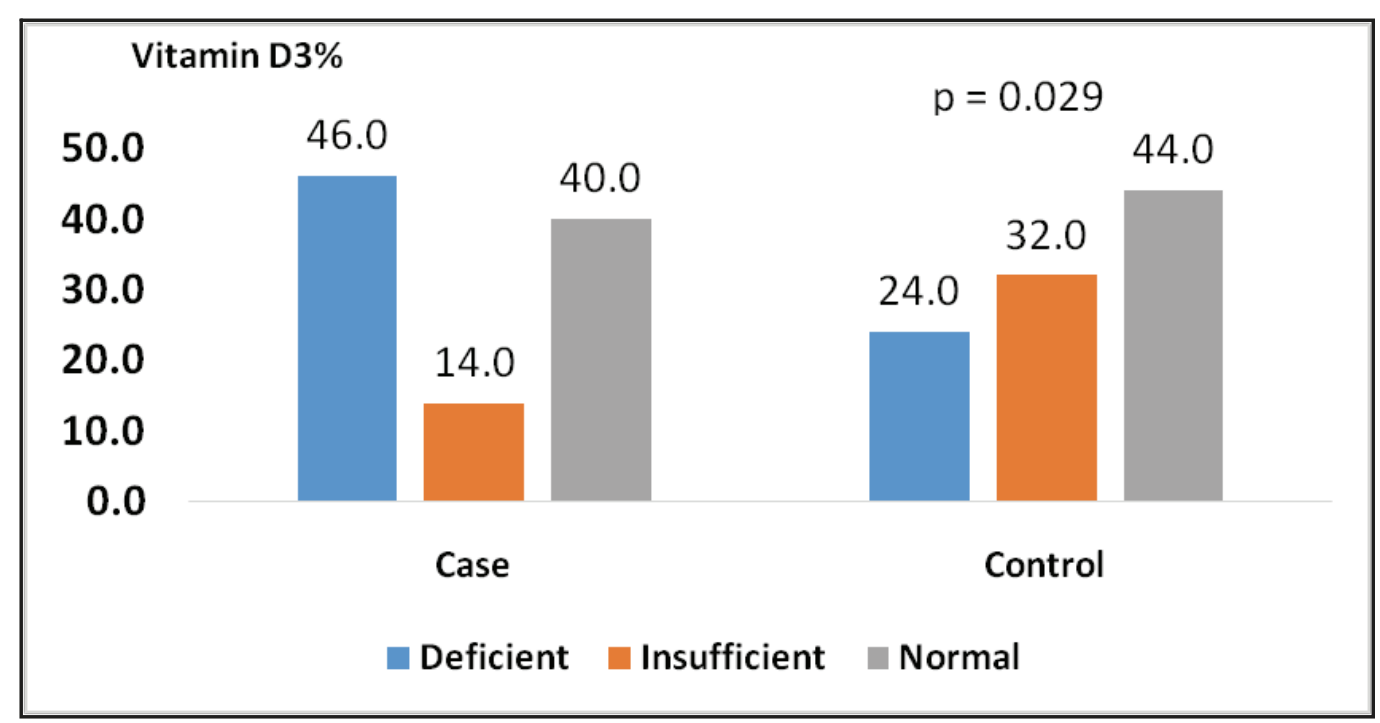

Figure 1: Comparison in the level of vitamin D3 between cases $(N=50)$ and control $(\mathrm{N}=50)$. 
Iron and vitamin D3 levels in infants admitted .......

It is evident in Table 2 that $24 \%$ of the cases had low $\mathrm{Hb}$ and vitamin D3 deficiency compared with only $6 \%$ of the control group $(P=0.031)$. The same pattern was observed in Table 3 and Figure 2, where $32 \%$ of the cases had iron and D3 deficiency compared with $6 \%$ of the control group $(P=0.004)$.

Table 2: Association between chest infection with hemoglobin and/or vitamin D3 deficiency.

Case Control Total

\begin{tabular}{lccccccc} 
& No. & $\mathbf{( \% )}$ & No. & (\%) & No. & (\%) & P value \\
\hline No Hb and D3 deficiency & 17 & $(34.0)$ & 25 & $(50.0)$ & 42 & $(42.0)$ & 0.031 \\
Either Hb or D3 is low & 21 & $(42.0)$ & 22 & $(44.0)$ & 43 & $(43.0)$ & \\
Hb low and D3 deficient & 12 & $(24.0)$ & 3 & $(6.0)$ & 15 & $(15.0)$ & \\
Total & 50 & $(100.0)$ & 50 & $(100.0)$ & 100 & $(100.0)$ & \\
\hline
\end{tabular}

Table 3: Association between chest infection with iron and/or vitamin D3 deficiency.

\begin{tabular}{lccccccc}
\hline & \multicolumn{2}{c}{ Case } & \multicolumn{2}{c}{ Control } & \multicolumn{2}{c}{ Total } \\
& No. & $(\%)$ & No. & $(\%)$ & No. & $(\%)$ & $P$ value \\
\hline No iron and D3 deficiency & 17 & $(34.0)$ & 21 & $(42.0)$ & 38 & $(38.0)$ & 0.004 \\
Either iron or D3 deficiency & 17 & $(34.0)$ & 26 & $(52.0)$ & 43 & $(43.0)$ & \\
Both iron and D3 are deficient & 16 & $(32.0)$ & 3 & $(6.0)$ & 19 & $(19.0)$ & \\
Total & 50 & $(100.0)$ & 50 & $(100.0)$ & 100 & $(100.0)$ & \\
\hline
\end{tabular}

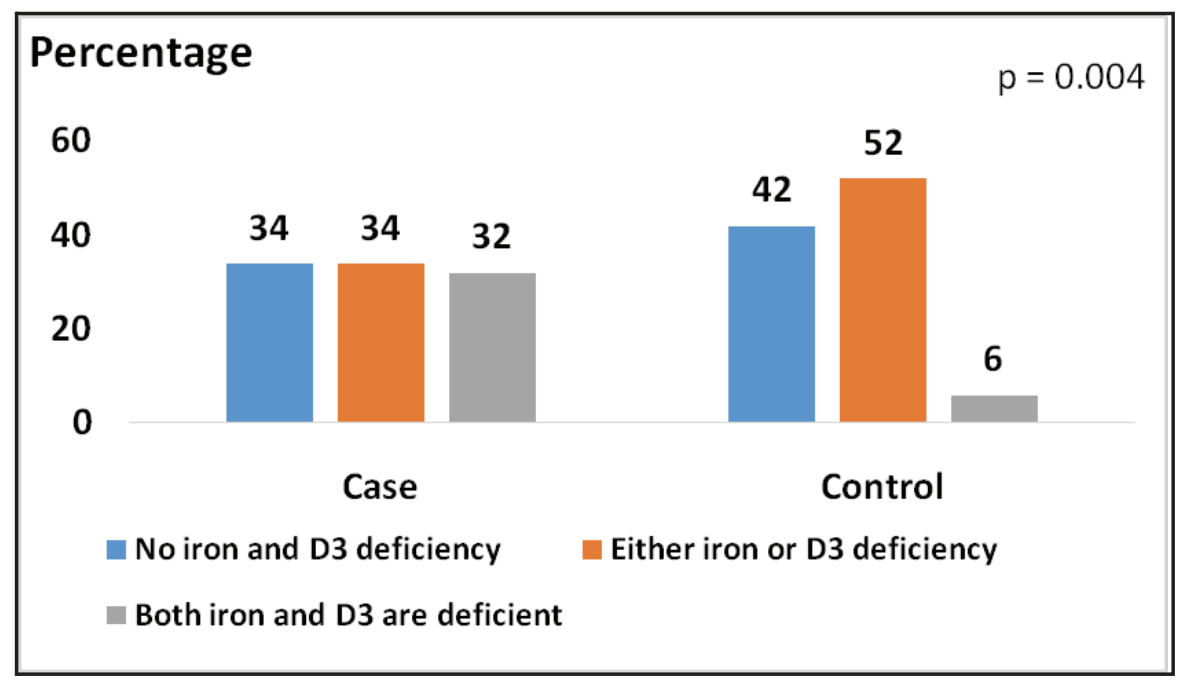

Figure 2: Association between chest infection with iron and / or vitamin D3 deficiency. 
In Table 4, only the anemic infants were included. The mean $\mathrm{Hb}$ of cases and controls was around $10 \mathrm{~g} / \mathrm{dl}(P=0.220)$. The mean of serum iron of the controls (44.25) was higher than that of the cases (33.42), but the difference was not significant $(P=0.197)$. The mean serum ferritin of cases (119.14) was significantly $(P=0.021)$ higher than that of the controls (64.00) (Table 4 \&Figure 3). Regarding the mean D3, it was higher among the controls than the cases, but the difference was not significant $(P=0.114)$.

Table 4: Means of the study parameters among cases and controls (anemic only).

\begin{tabular}{|c|c|c|c|c|c|}
\hline & \multicolumn{2}{|c|}{ Cases $(n=22)$} & \multicolumn{2}{|c|}{ Controls $(n+16)$} & \multirow[b]{2}{*}{$P$ value } \\
\hline & Mean & $( \pm S D)$ & Mean & $( \pm S D)$ & \\
\hline $\mathrm{Hb}$ & 10.100 & $(0.867)$ & 10.400 & $(0.482)$ & 0.220 \\
\hline Iron & 33.427 & $(26.043)$ & 44.250 & $(23.669)$ & 0.197 \\
\hline Ferritin & 119.141 & $(76.226)$ & 64.006 & $(58.502)$ & 0.021 \\
\hline Vitamin D3 & 21.436 & $(19.573)$ & 31.125 & $(16.139)$ & 0.114 \\
\hline
\end{tabular}

\section{Mean serum ferritin $\mathrm{ng} / \mathrm{ml}$}

$$
p=0.021
$$
140.0
120.0
100.0
80.0
60.0
40.0
20.0
0.0

119.1

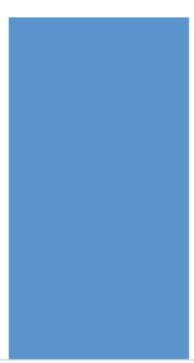

64.0

Case

Control

Figure 3: Difference in the level of mean serum ferritin between anemic cases $(\mathrm{N}=22)$ and anemic control $(\mathrm{N}=16)$. 


\section{Discussion}

In the present study, out of 38 anemic infants, $22(57.8 \%)$ had chest infection, and out of 62 non-anemic infants, 28 (45.1) had chest infection; this was statistically insignificant $(P=0.216)$. These percentages were much higher in another study by Saleh et al., ${ }^{10}$ which were $93 \%$ for anemic and $8 \%$ for non-anemic. They explained their results by the presence of some risk factors like overcrowding, ignorance, poor sewages, living in rural areas and pollution. Lower percentages were reported in Lebanon by Mourad et al. ${ }^{20}$, which were $37.5 \%$ in the anemic group and $14.5 \%$ in the nonanemic group. The relationship between anemia and LRTI can be explained by that oxygen and carbon-dioxide transportation is mainly facilitated by $\mathrm{Hb}$, in addition, that $\mathrm{Hb}$ acts as a buffer for nitric oxide and other body derangements. ${ }^{21}$ It is well known that the most common cause of anemia is IDA, ${ }^{7}$ and iron is an essential element for the normal development of the immune system. It is a vital element for appropriate cell differentiation and cell growth. It is also a substantial component of nitrous oxide generating enzymes and peroxide generating enzymes that are important for proper enzymatic functioning of the immune cells. Furthermore, it is involved in the regulation of production and action of cytokines and in the cell mediated immunity development. ${ }^{22}$ The results showed that there was a lower value of mean serum iron among anemic cases than anemic controls $33.427 \mu \mathrm{g} / \mathrm{dl}$ and $44.250 \mu \mathrm{g} / \mathrm{dl}$, respectively, but it was statistically insignificant $(P=0.197)$. We found that there are statistically significantly higher mean serum ferritin levels among anemic cases than among anemic controls $(P=0.021)$. Nearly similar results reported by Saleh et al., ${ }^{10}$ but it was statistically significant for both mean serum iron and mean serum ferritin among the anemic cases and controls; this finding can be explained by that infection may affect iron panel studies by elevating the ferritin values as an acute phase reactant, and decreasing the iron, ${ }^{23}$ or explained by the role of iron in immune response and resistance against infections. So, iron deficiency leads to reduced immunity and increases the incidence of infection. ${ }^{24,25}$ Also, in the present study, the cases had lower vitamin $D$ levels while the controls had higher vitamin $\mathrm{D}$ levels; it was deficient among $46 \%$ of the cases compared with $24 \%$ of the controls that was a significant correlation with a $P$ value of 0.029 . A nearly similar study done in India by Madhu et al., ${ }^{26}$ found a significant correlation between vitamin $\mathrm{D}$ levels and ALRTI and that $70 \%$ of the cases had VDD while only $16 \%$ of the control group had VDD with a $P$ value of less than 0.001 . Opposite to our findings, there was no significant correlation between levels of vitamin $D$ with both susceptibility and severity of LRTI in a study done in Turkey, ${ }^{27}$ but they found that low levels of vitamin $D$ presented at a high rate among most of the participants of the study. The relation between VDD and susceptibility to infections can be explained by the immunological role of Vitamin $D$. It has been found that VDD considerably reduced the percentage of circulating polymorph nuclear neutrophils, these neutrophils are important cells in innate immune responses which moves into the tissues of lungs and performs phagocytosis by killing the viruses and bacteria. ${ }^{28}$ It has been discovered that vitamin $D$ regulates particular endogenous antimicrobial peptides expression in the immune cells. So this finding increases the attention to the possible role of vitamin $D$ in modifying the immune response to different infectious diseases. ${ }^{29}$ In our study, $24 \%$ of the cases had both low $\mathrm{Hb}$ level and vitamin D3 deficiency compared with only $6 \%$ of the control group, and this finding was significant $(P=0.031)$. In agreement with our findings, Madhu et al. found a significant correlation between severe ALRI and combined low levels of $\mathrm{Hb}$ and low vitamin $D$ levels, $P<0.001 .^{26}$ The correlation between deficiency of 
vitamin $\mathrm{D}$ and low levels of hemoglobin can be referred to the stimulatory impact of vitamin $D$ on erythroid precursors because vitamin $D$ receptors have been discovered in different non-renal target tissues including also the bone marrow. ${ }^{30}$

\section{Conclusion}

In conclusion, both vitamin D3 and iron, especially together, play a role as an enhancer of immunity against chest infections in infants and better to be estimated to evaluate these cases.

\section{Competing interests}

The authors declare no competing interests.

\section{References}

1. Barson WJ, Kaplan SL, Torchia MM. Epidemiology, pathogenesis, and etiology of pneumonia in children. Up to Date Versión 2008;15.

2. Graham SM, English M, Hazir $T$, Enarson $P$. Challenges to improving case management of childhood pneumonia at health facilities in resource-limited setting. Bull WHO 2008; 86:349_ 55.

3. Rudan I, Boschi-Pinto C, Biloglav Z, Mulholland K, Campbell $\mathrm{H}$. Epidemiology and etiology of childhood pneumonia. Bull World Health Organ 2008; 86:408-16.

4. Agweyu A, Opiyo N, English M. Experience developing national evidence based clinical guidelines for childhood pneumonia in a lowincome setting-making the GRADE? BMC Pediatr 2012; $12: 1$.

5. Piedra PA, Stark AR, Redding G, Edwards MS. Bronchiolitis, infants and children: clinical features and diagnosis, UpToDate [Last updated March 13, 2013].

6. Hussain SQ, Ashraf M, Wani JG, Ahmed J. Low hemoglobin level a risk factor for acute lower respiratory tract infections (ALRTI) in children. $\mathrm{J}$ Clin Diagn Res 2014; 8(4):PC01-03.

7. WHO. Technical updates of the guidelines on the Integrated Management of Childhood Illness (IMCl): evidence and recommendations for further adaptations. Geneva, Switzerland: Department of Child and Adolescent Health and Development; 2005.

8. Ramakrishnan K, Borade A. Anemia as a risk factor for childhood asthma. Lung India: official organ of Indian Chest Society 2010; 27(2):51.

9. Bont L, Heijnen C, Kavelaars A, van Aalderen W, Brus F, Draaisma J, et al. Local interferon-levels during respiratory syncytial virus lower respiratory tract infection are associated with disease severity. J Infect Dis 2009; 184:355-8.

10. Saleh ON, Ismail MM, Hamed MH, Bassiony ME. Hemoglobin level and iron profile as risk factors for lower respiratory tract infections among children. Egypt J Haematol 2017; 42(1):14

11. DeLuca HF. Overview of general physiologic features and functions of vitamin D. Am J Clin Nutr 2004; 80(6):1689-96.

12. Bouillon R, Rosen CJ, Mulder JE. Vitamin D and extraskeletal health. UpToDate [Last updated. December 18, 2012].

13. Grant WB. Variations in vitamin D production could possibly explain the seasonality of childhood respiratory infections in Hawaii. Pediatr Infect Dis J 2008; 27(9):853.

14. Larkin A, Lassetter J. Vitamin D deficiency and acute lower respiratory infections in children younger than 5 years: identification and treatment. J Pediatr Health Care 2014; 28(6):572 -82 .

15. Sectish TC, Prober CG. Pneumonia. In: Behrman RE, Kliegman R, Jenson HB, ed. Nelson Text Book of Pediatrics. $17^{\text {th }}$ ed. Philadelphia: Saunders; 2004. P. 1401.

16. Burtis CA, Edward RA. Principles of colorimetric determination of unsaturated iron binding capacity in serum. Tietz textbook of clinical chemistry. $4^{\text {th }}$ ed. Philadelphia, Pennsylvania, USA: Elsevier Saunders; 2006. P. 2195-7.

17. WHO. Serum ferritin concentrations for the assessment of iron status and iron deficiency in populations. Vitamin and Mineral Nutrition Information System. Geneva, World Health Organization; 2011 (WHO/NMH/NHD/ $\mathrm{MNM} / 11.2$ ).

18. Balasubramanian $\mathrm{S}$, Dhanalakshmi $\mathrm{K}$ Amperayani S. Vitamin $D$ deficiency in childhood-A review of current guidelines on diagnosis and management. Indian Pediatr 2013; 50(7):669-75.

19. World Health Organization. Haemoglobin concentrations for the diagnosis of anaemia and assessment of severity; 2011. (Accessed March 3, 2018, at http://www.who.int/vmnis/indicators/ haemoglobin/en).

20. Mourad S, Rajab M, Alameddine A, Fares M, Ziade F, Merhi BA. Hemoglobin level as a risk factor for lower respiratory tract infections in Lebanese children. N Am J Med Sci 2010; 2(10):461.

21. Ganong WF. Gas Transport between the Lungs and the Tissues. In: Barrett KE, Boitano S, Barman SM, Heddwen L. Brooks Review of Medical Physiology, Ganong W.F. (Ed.) $22^{\text {nd }}$ ed. New York:McGraw-Hill; 2005. P. 666-9.

22. Beard JL. Iron biology in immune function, muscle metabolism and neuronal functioning. J Nutr 2001; 131:568-80.

23. Tansu S, Tulin K, Betul T. Effects of acute infection on hematological parameters. Pediatric 
Hematol Oncol 2004; 21:511-8.

24. Schaible UE, Kaufmann SH. Iron and microbial infection. Nat Rev Microbiol. 2004; 2:946-53.

25. Johnson EE, Wessling-Resnick M. Iron metabolism and the innate immune response to infection. Microbes Infect 2012; 14(3):207-16.

26. Madhu GN, Siva Saranappa SB, Manasa G. Association between low hemoglobin level, vitamin $\mathrm{D}$ deficiency and acute lower respiratory tract infections in children aged 6 months to 5 years. Curr Pediatr Res 2017; 21(1):181-5.

27. Şişmanlar T, Aslan AT, Gülbahar Ö, Özkan S. The effect of vitamin D on lower respiratory tract infections in children. Turk Pediatri Ars 2016; 51(2):94.

28. Banajeh SM. Nutritional rickets and vitamin D deficiency-Association with the outcomes of childhood very severe pneumonia: A prospective cohort study. Pediatr Pulmonol 2009; 44:120715.

29. Liu PT, Stenger S, Li H, Wenzel L, Tan BH, Krutzik SR, et al. Toll-like receptor triggering of a vitamin D-mediated human antimicrobial response. Science 2006; 311(5768):17703.

30. Norman AW. Vitamin D receptor: new assignments for an already busy receptor. Endocrinology 2006; 147(12):5542-8. 